\title{
Pentetic Acid
}

National Cancer Institute

\section{Source}

National Cancer Institute. Pentetic Acid. NCI Thesaurus. Code C460.

An edetate and a chelating agent used in preparing radiopharmaceuticals. Pentetic acid (DTPA) has strong affinity for iron but also shows affinities for other heavy metals, thereby is used in the treatment of iron-storage disease and poisoning from heavy and radioactive metals. DTPA may chelate metallic moieties of unbound, extracellular radioimmunotherapeutics, thereby aggregating radioimmunotherapeutics locally to higher concentrations, and improving tumor cell radiocytotoxicity, while sparing normal tissues from the radiocytotoxic effects. In addition, DTPA is used in radioimaing procedures when complexes with radioisotopes, ex., Tc $99 \mathrm{~m}$ or In 111. 